\title{
Research on the classification and development investment strategy of
}

\author{
power grid enterprise \\ Yungao Ma, Yazong Mai*, Wan He \\ State Grid Energy Research Institute \\ Beijing, China \\ *Corresponding author: Yazong Mai, maiyazong@163.com
}

\begin{abstract}
The scientific arrangement of gird development investment is the key to the development of power grid enterprises. Considering the provincial electricity consumptions and grid structures, a twodimensional classification model formed by the per capita electricity consumption and the power grid quality is established for the provincial power grid enterprises, with 27 provincial clustering results feedback to guide the development of power grid enterprises investment strategy. After that, the implementation of investment control measures with regional differences are proposed in the aspects of power grid upgrading and reconstruction, own fund project, loan financing and so on, which could ensure the investment arrangements of the power grid enterprise more accurate and efficient, meanwhile it could provide effective support for the whole process of the development investment of power grid enterprises to promote the closed-loop control.
\end{abstract}

Keywords: grid development ; investment strategy; classification model; differential management

\section{Introduction}

The scientific arrangement of investment plan is directly related to the implementation of corporate strategy, which will promote the company's management into the group operating and intensive configuration transition ${ }^{1}$. It has the overall effect of guiding the development of enterprises, coordinating development speed, quality and structure.

At present, the power grid enterprises in deepening the power system reform of the critical period, power demand growth down, transmission and distribution price reform to bring the expected price reduction, business development is facing greater pressure ${ }^{2}$. It's important to recognize how to put forward comprehensive investment plans according to differentiated 
strategy and allocate the investment funds rationally. Therefore, it's necessary to make a further research on the investment strategy.

The paper will analyze the problems in the followings: How to establish the classification evaluation model of the provincial companies? How to make a scientific investment among the provincial enterprises according to the classification model? In view of the above problems, the investment arrangements of power grid enterprises should take into account the development needs and investment capacity, and further balance the allocation of resources between different regions ${ }^{3}$. The development investment must be more accurate and efficient, so as to improve the investment level.

\section{Research on classification evaluation model of power grid enterprise}

\subsection{Model building ideas}

In order to solve the reasonable arrangement on how to allocate funds among different provincial companies, this paper first evaluates the electricity consumption and grid structure of the provincial companies. Then, this paper carries out scientific classification management accordingly and puts forward suggestions the investment distribution strategy among different types of provincial companies.

This paper constructs a two-dimensional classification model of "electricity consumption per capita - power grid quality”, which would guide the future distribution decision in the power grid enterprise. 1) The electricity consumption per capita. Considering the power system reformation, the actual income of power grid enterprises is related to electricity consumption and its price. Therefore, it is necessary to increase investment in areas where electricity consumption growth is relatively stable or where there is a higher growth space. 2) The power grid quality. The power grid quality is an important index reflecting the investment demand of each region. For areas where the grid quality is poor or requires a lot of investment, these areas should be valued when making investment strategy.

\subsection{Comprehensive evaluation of electricity consumption per capita}

We use two indexes of living-electricity consumption and total electricity consumption to evaluate the electricity consumption per capita. Considering the living-electricity consumption of different provinces, Fujian (899 kWh/p), Beijing (805 kWh/p), Zhejiang (801 $\mathrm{kWh} / \mathrm{p}$ ) and other units have higher living-electricity consumption; Tibet (232 kWh/p), Xinjiang (339 kWh/p) are relatively low among the 27 units. Considering the total electricity 
consumption of different cities, Ningxia (11388 kWh/p), Qinghai (13426 kWh/p) and other units have higher total electricity consumption. Tibet (1298 kWh/person), East of Inner Mongolia (1609 kWh/p) and other units are relatively low among the 27 units.

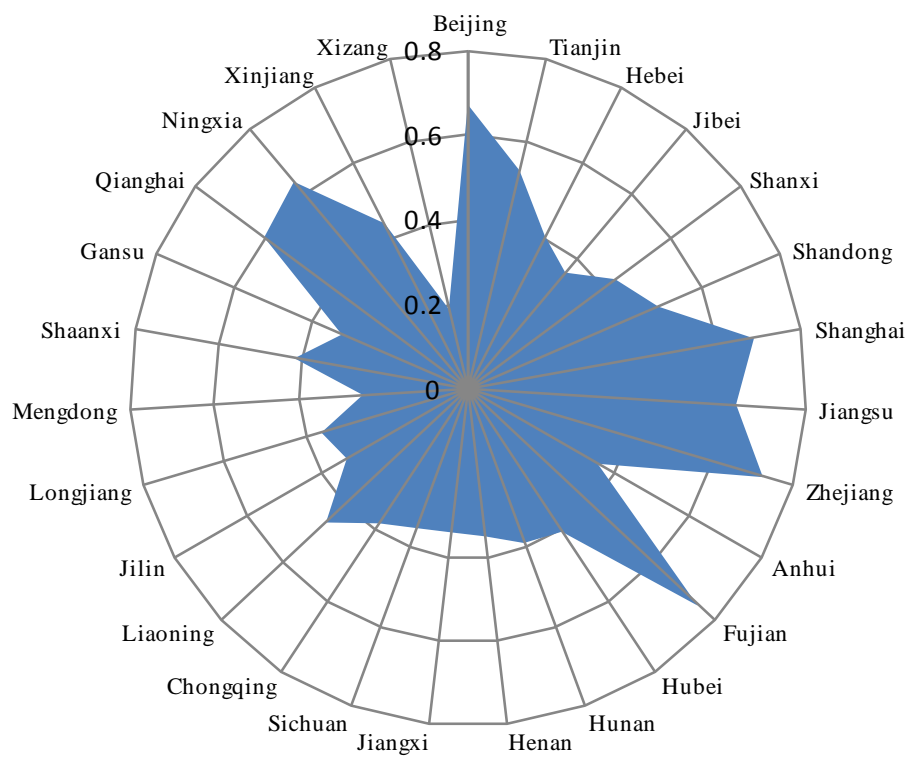

Fig.1- Evaluation results of electricity consumption per capita for each province

Considering the comprehensive evaluation of electricity consumption per capita, we have the following equation ${ }^{4}$ : the comprehensive evaluation score of electricity consumption per capita $=$ Weight $\times$ living-electricity consumption + weight $\times$ total electricity consumption. The results show that Fujian, Zhejiang, Shanghai and other units have higher scores among the 27 units; the score of Tibet and East of Inner Mongolia are relatively low (Fig.1).

\subsection{Comprehensive evaluation of power grid quality}

This paper build an evaluation index system of grid development quality from two aspects: the grid status and the power supply quality. The grid status includes four indicators, i.e., capacity-load ratio, overload ratio, N-1 pass rate and interconnection rate ${ }^{5}$. The power supply quality includes power supply reliability rate and voltage eligibility rate.

Considering the grid situation, we have the following equation: the scores of grid situation = weight $\times$ capacity-load ratio + weight $\times \mathrm{N}-1$ pass rate + weight $\times$ interconnection rate. The results show that: Tianjin, Shanghai, Jiangsu, Zhejiang, Shaanxi and other units are much better; Xinjiang, Tibet and Heilongjiang are relatively poor. 
Considering the quality of power supply, we have the following equation: the scores of the power supply quality $=$ weight $\times$ power supply reliability rate + weight $\times$ voltage eligibility rate. The results show that: Shanghai, Shandong, Jiangsu, Zhejiang, Beijing and other units have higher power supply quality; East of Inner Mongolia, Qinghai and Heilongjiang are relatively poor.

Considering the comprehensive evaluation of power grid quality, we know that ${ }^{6}$ : the power grid quality evaluation score $=$ weight $\times$ grid situation + weight $\times$ power supply quality. The results show that: the quality of power grid development in Shanghai, Jiangsu, Zhejiang, Tianjin and other units have stronger power grid quality; Tibet, East of Inner Mongolia and Xinjiang have poor grid development (Fig.2).

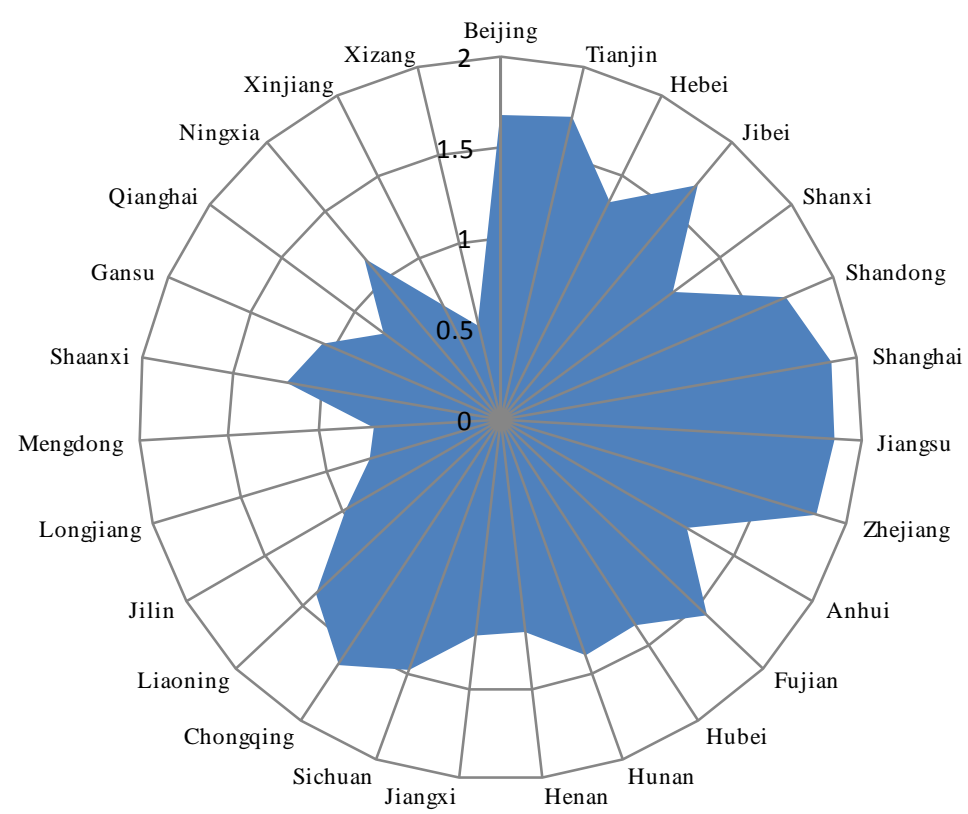

Fig.2- Evaluation results of power grid quality of each province

\section{Research on investment strategy based on the classification model}

\subsection{The two-dimensional classification model}

This paper constructs a two-dimensional classification model of "electricity consumption per capita - power grid quality”. Therefore, the 27 provincial companies could be divided into four types (Fig.3): 1) higher electricity consumption per capita \& strong power grid quality; 2) lower electricity consumption per capita \& strong power grid quality; 3) lower electricity consumption per capita \& poor power grid quality; 4) higher electricity consumption per capita \& poor power grid quality. 


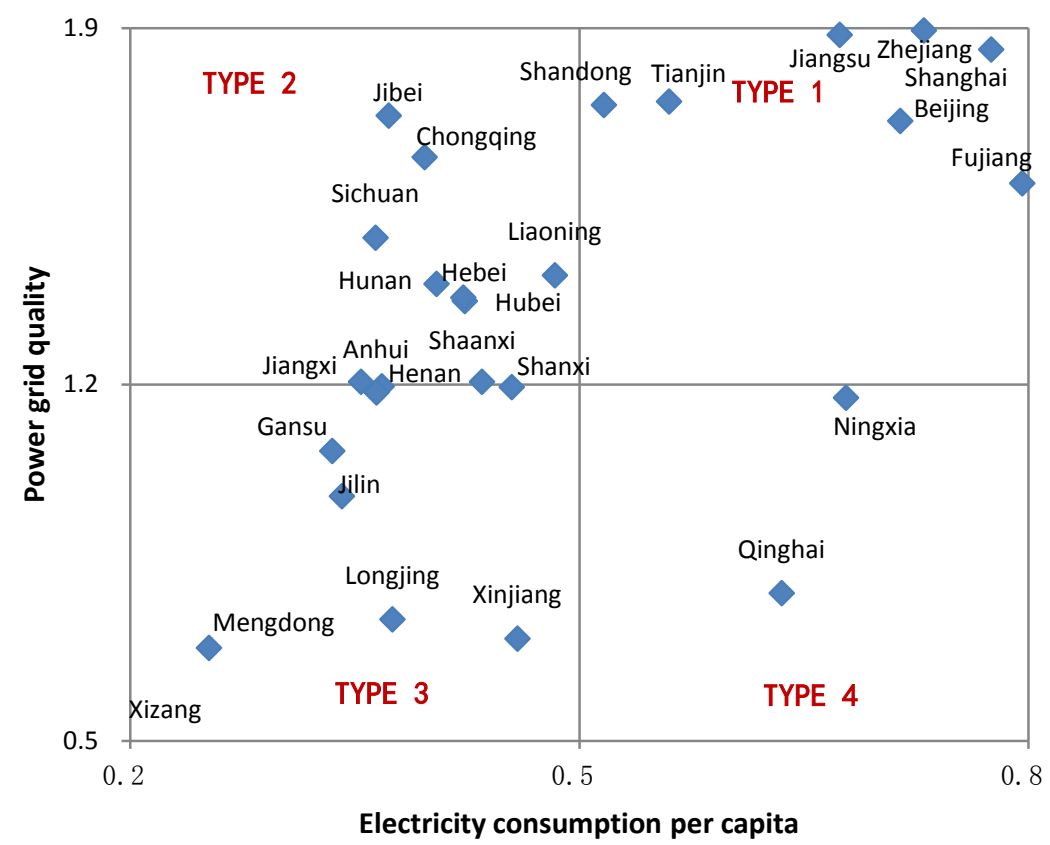

Fig.3- Classification results of electricity consumption per capita and power grid quality

\subsection{Differentiated investment strategies by region}

Based on the classification model of the 27 provincial companies, we take a further account about its development capacity and different characteristics (available funds, asset-liability ratio, etc.). After that, this paper proposes the investment strategy for different types of provincial companies.

1) The first type "higher electricity consumption per capita \& strong power grid quality" including Jiangsu, Zhejiang and other seven units. These provincial companies should maintain a steady investment strategy. If the investment capacity is sufficient, SGCC should meet the investment needs of these units.

2) The second type "lower electricity consumption per capita \& strong power grid quality" including Hebei, Chongqing and other 12 units. These provincial companies should pay more attention on the development of power grid transformation in order to overcome the bottleneck of hindering. It's necessary to avoid investment duplication and investment waste for these units.

3) The third type "lower electricity consumption per capita \& poor power grid quality" including Tibet, East of Inner Mongolia and other 6 units. These provincial companies are the key units of SGCC strengthen control. In the development of investment arrangements, SGCC should focus on the "bottleneck" projects and technological transformation projects. 
4) The fourth type "higher electricity consumption per capita \& poor power grid quality" including Ningxia and Qinghai. It is necessary to increase the investment level to improve the power grid quality and quantity. At the same time, it is necessary to try the financial initiatives to solve the problem of insufficient investment capacity in the national policy framework.

\section{Conclusions}

This paper clarifies that the power grid enterprises should establish the classification control model in the investment arrangement. Specially, this paper constructs a two-dimensional classification model of "electricity consumption per capita - power grid quality”. For Ningxia, Qinghai and other units with "higher electricity consumption per capita \& poor power grid quality”, it is necessary to increase investment of these units. At the same time with the national policy initiatives, as far as possible for the government financial funds to solve the problem of lack of investment capacity.

\section{Acknowledgment}

This paper is sponsored by the Key Project "Research on the Integrated Planning Management System and Resource Input Optimization Technology in Electric Power Reform” of State Grid Corporation of China (GN: 15-JS-191).

\section{References}

1. F. q. Zhang, Luo H., Liu M. Z. , Gao Z. P., Li N., Wen F. S., A Gini Coefficient Based Investment Allocation Model for Power Networks and Its Application, Electric Power Construction, 2016, 01:9-14.

2. W. T. Cui, H. Liu, W. h. Yang, X. Y. Wang, S. Y. Ji, Study on Distribution Network Investment Allocation and Project Selection Optimization, Electric Power, 2015, 11:149-154.

3. Q. H. Yi, Study on a Decision-Making Model for the Investment Allocation of Power Distribution Networks , Chongqing University, 2015.

4. L. E. Fang, H. Z. Cheng, L. Liu, Z. Wu, W. Hu, Evaluation of $10 \mathrm{kV}$ Distribution Network Investment Allocation Based on Multi-Index System,East China Electric Power, 2014, 06:1092-1097. 
5. W. He, F. S. Zhong, Y. Chang, Study on Investment Performance Evaluation of Grid Enterprise,Technology Economics, 2011, 01:78-84.

6. X. C. Ma, Research on the Optimal Balance of Provincial Electric Grid Unified Planning Indicator System,North China Electric Power University, 2012. 